\title{
Fear of Loneliness: Development and Validation of a Brief Scale
}

\author{
José Ventura-León', Andy Rick Sánchez-Villena', Tomás Caycho-Rodríguez', \\ Miguel Barboza-Palomino ${ }^{1}$ and Andrés Rubio ${ }^{2,3 *}$
} ${ }^{1}$ Facultad de Salud, Escuela de Psicología, Universidad Privada del Norte, Lima, Peru, ${ }^{2}$ Facultad de Enfermería, Universidad
Andres Bello, Santiago, Chile, ${ }^{3}$ Facultad de Psicología, Universidad Diego Portales, Santiago, Chile

This research aims to develop and validate a Spanish version of The Brief Scale of Fear of Loneliness (BSFL). Participants were 1385 youth and adults, 347 from a pilot sample and 1032 from the final version, whose ages were in the range of 18 to 40 years. Two instruments, the Rosenberg Self-Esteem Scale and the De Jong Gierveld Loneliness Scale, in their Peruvian versions, were used to support the relationship with other variables. Results show that the BSFL should be interpreted as a one-dimensional measure, the same ones that were examined at the exploratory level and verified at the confirmatory moment (RMSEA $<0.08, \mathrm{CFI}>0.95$ ), and its reliability is considered good

OPEN ACCESS

Edited by: Dario Paez, University of the Basque Country, Spain

Reviewed by: Ginés Navarro-Carrillo, University of Jaén, Spain Dario Monzani, University of Milan, Italy

*Correspondence: Andrés Rubio a.rubiorivera@uandresbello.edu

Specialty section:

This article was submitted to Personality and Social Psychology, a section of the journal Frontiers in Psychology

Received: 14 July 2020 Accepted: 22 September 2020 Published: 23 October 2020

Citation: Ventura-León J, Sánchez-Villena AR, Caycho-Rodríguez T, Barboza-Palomino M and Rubio A (2020) Fear of Loneliness:

Development and Validation of a Brief Scale. Front. Psychol. 11:583396. doi: 10.3389/fpsyg.2020.583396 $(\omega>0.88)$. In addition, the quality of the item content was reviewed by six expert judges for relevance and validity, with Aiken's $V$ being greater than 0.70 . It is concluded that the BSFL is a valid and precise short instrument that can be used in future research studies.

Keywords: loneliness, solitude, belonging, instrument validation, isolation, fear

\section{INTRODUCTION}

\section{Loneliness}

It has been known for a long time that $71 \%$ of people between 18 and 24 years old report feeling lonely sometimes or often, and between 25 and 34 years old the figure drops slightly to $69 \%$ (Parlee, 1979). Recent figures reveal $17 \%$ of people between 18 to 24 years old and 25 to 35 years old said they felt alone quite often and very often, respectively, also experiencing anxiety and concern about feeling alone (YOUGOV, 2016). Likewise, according to a prevalence study carried out in the United Kingdom, it is known that women under 25 years of age present greater amounts of loneliness than men, with 9 and 6\% respectively, claiming to always feel alone (Victor and Yang, 2012). Similar results are reported in university students in Amsterdam, where the prevalence of loneliness reaches $23 \%$ (Pijpers, 2017).

Loneliness is characterized by a lack of satisfaction in interpersonal relationships (Andersson, 1993), which arises when support and social networks are impaired (Perlman and Peplau, 1981), and the individual experiences feelings of isolation, not belonging, incomprehension, rejection (Rook, 1984), or lack of company (Francis, 1976). Furthermore, loneliness includes deficiencies, disagreements, isolation, and psychological pain manifested in sadness, boredom, and a feeling of emptiness (Stein and Tuval-Mashiach, 2015).

Loneliness has been linked to many other variables. For example, in the biological field, it has been observed that loneliness has been related to different variables such as blood pressure, cortisol levels, hypersensitivity to stressors and immunosuppression (Brown et al., 2017, 2019). From a clinical point of view, there is evidence of a relationship with suicidal ideation and behavior (Chang et al., 2017; Calati et al., 2018), depressive symptoms, and social anxiety (Lasgaard et al., 2011; 
Danneel et al., 2019). Regarding family related factors, a relationship has been found with the interaction with parents in their positive communication and time together (Majorano et al., 2017), with family cohesion and adaptability (Fujimori et al., 2017), and with stress in the academic context (Stoliker and Lafreniere, 2015). Finally, in the intra and interpersonal dimensions, it has been associated with shyness (Bian and Leung, 2015; Muyan et al., 2018), avoidance (Demirli and Demir, 2014), anxiety to speak (Odaci and Kalkan, 2010), and self-esteem (Chiao et al., 2019). On the other hand, loneliness has a mediating effect on the relationship between excessive use of social networks and real-life social interaction in university students (Ndasauka et al., 2016), as well as on the relationship between social skills and depressive and anxious symptoms (Moeller and Seehuus, 2019). Furthermore, it is known that loneliness is greater in men than in women (Wiseman et al., 1995), however, with small effect sizes (Maes et al., 2019).

Despite the fact that loneliness has been studied in relation to many variables from various fields, there are no studies that explore fear of the experience of loneliness per se, which has been considered for a time as painful and acute in young and adult population, more than in other ages (Rokach, 2000).

\section{Fear of Loneliness}

Fear is an unpleasant experience that implies a degree of awareness of the individual (Uribe et al., 2007), with its etymology being associated with the suspicion of future danger or harm (Real Academia and Española, 2014). Despite this, the term fear can be understood as an attitude toward something (Uribe et al., 2007; Simkin and Quintero, 2017) that triggers behaviors of fight, escape, or avoidance (Bay and Algase, 1999) to the topic, situation or place (Wong et al., 1997), that are products of the beliefs that the individual experiences and generates, and have an impact in their daily life (Al-Namankany et al., 2012). Nonetheless, the terms fear and anxiety are used interchangeably (Tomás-Sábado, 2016), although the latter has a more cognitive component (Whitley, 1992; Catherall, 2003), while the first one is more behavioral in nature (Blanchard and Blanchard, 1990a,b). Despite this, there is a reciprocal interaction between them (Bandura, 1977).

In this sense, the Fear of Loneliness (FL) can be understood as an attitude of avoidance accompanied by worrying thoughts and feelings of abandonment that the individual experiences when she/he is alone. This definition can be used to interpret the scores on the scale.

The notion of studying the responses of fear toward a specific object is not new since it is known that there are scales that measure fear of negative evaluation (Gallego et al., 2007; Zubeidat et al., 2007), of death (Tomás-Sábado et al., 2007; López and Calle, 2008), flying (Dongil and Wood, 2009), and even fear of dental treatment (Armfield, 2010; Al-Namankany et al., 2012; Ibrahim et al., 2017). Therefore, it is not strange to conceptualize loneliness as a specific fear.

The problem of loneliness takes on particular relevance in the current context, considering aspects such as the lack of sense of belonging linked to the increasing levels of individualism (Santos et al., 2017). In addition, the phenomenon of sustained growth in the use of social networks must also be considered, which in some cases is associated with the feeling of loneliness (Song et al., 2014). In this sense, and considering that the feeling of loneliness has been shown to be associated with self-esteem in many different populations (Creemers et al., 2012; DomagałaKrecioch and Majerek, 2013; Kong and You, 2013; Tian, 2016), it could be thought that the fear of loneliness today plays a key role in people's well-being, as well as in the constitution of their identities. Due to the above, it is necessary to design and validate instruments that measure this particular construct.

\section{The Present Research}

There are various instruments that have measured loneliness since the 1970s (Russell et al., 1978), 80s (Russell et al., 1980; De Jong-Gierveld and Kamphuls, 1985), 90s (Russell, 1996; Cramer and Barry, 1999) as well as periods after 2000 (Hughes et al., 2004; Maes et al., 2015). Despite this, there is no instrument that measures FL; with the closest being the Fear Survey Schedule (Rubin et al., 1969). Although these authors developed a scale with 122 items, five of which are related to fear of isolation or loneliness, they do so in a general way, without considering criteria that allow addressing the phenomenon in a more specific and complete way. In this context, the purpose of the study is to develop and validate a Brief Scale of FL in youth and adults, considering the content-based evidence through expert judgment, testing the internal structure of the scale through exploratory and confirmatory analysis, the calculation of the reliability using the omega coefficient and the establishment of the invariance according to sex.

\section{MATERIALS AND METHODS}

\section{Participants}

Participants were 1385 youth and adults split in two groups. The first one was made up of 347 people between 18 and 40 years old (Average $=23.26 ; S D=6.51$ ), with 204 being women and 143 men. With these participants the EFA was performed. The participants were university students from the faculties of Health Sciences (49.86\%), Business (20.75\%), Engineering (12.97\%), Architecture and Design (6.63\%) and Rights and Political Sciences $(4.03 \%)$, which were in academic cycles from 1 st to 10 th. The second group consisted of 1,032, whose ages also ranged from 18 to 40 years $($ Mean $=21.09$; $S D=3.38)$, with 795 being women and 237 men, and whose responses were used for the CFA. It is worth mentioning that these young people and adults were university students. From the faculties of Health Sciences (89.44\%), Engineering (3.88\%), Administration (2.62\%), Architecture and Design (1.55\%), Business (1.16\%), Law and political science (1.07\%), and Communications (0.3\%). All the participants were people residing in the northern area of Metropolitan Lima.

\section{Instruments}

\section{The Brief Scale of Fear of Loneliness (BSFL)}

It is made up of five items belonging to a single factor. Possible responses indicated frequency, where $0=$ Never; $1=$ Rarely; 


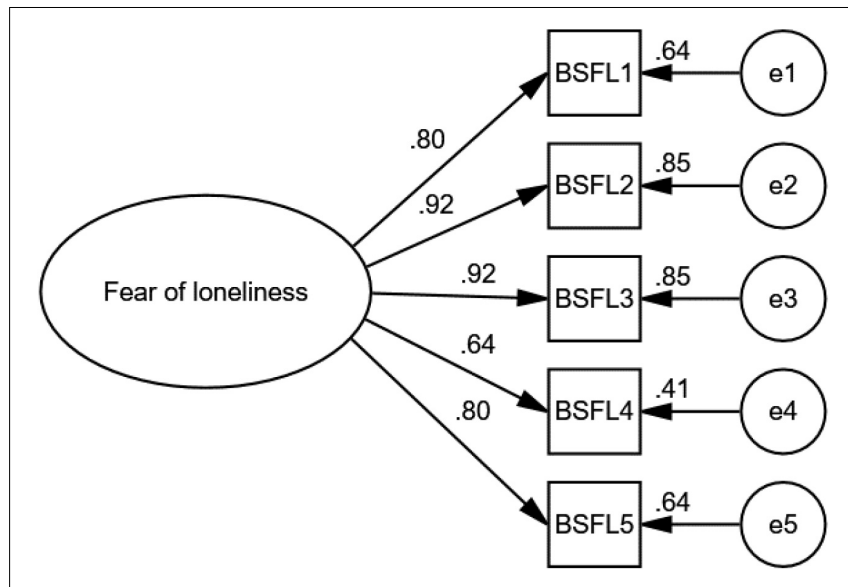

FIGURE 1 | Factorial structure of the BSFL.

$2=$ Sometimes; 3 = Almost always; and $4=$ Always. Psychometric properties are the object of the present study.

\section{The Rosenberg Self-Esteem Scale ([RSE]; Rosenberg, 1965)}

It made up of 10 items, distributed into five negative or inverse items, and five positive items, with a Likert scale ranging from 1 to 4. The psychometric properties of the RSE in Peru were adequate (Ventura-León et al., 2018).

\section{The De Jong Gierveld Loneliness Scale ([DJGLS]; De Jong-Gierveld and Kamphuls, 1985)}

It is a scale made up of 11 items with a scale ranging from 0 to 3 . However, the answers must be dichotomized, so that the DJGLS reaches a maximum score of 11 points. Psychometric properties in Peru were analyzed by Ventura-León and Caycho (2017).

\section{BSFL Construction Procedures}

For the construction of the BSFL, the recommendations of the International Test Commission were followed (International Test Commission [ITC], 2018). Initially, different databases (Redalyc, Scielo, Scopus, Proquest, Google Scholar, Taylor and Francis, Sage) were reviewed in order to search for different theories where FL is addressed. First, the variable was operationalized by means of a specification table where the definition was set and five items emerged. Second, the five items were submitted to the scrutiny of six expert judges who rated the relevance and validity of the items on a scale of 0 (not at all) to 3 (totally); furthermore, the responses were quantified using Aiken's V (Ventura-León, 2019). Third, the BSFL was applied to a pilot sample of 347 people who signed an informed consent and then answered the scale; their answers were subjected to an exploratory factor analysis to verify the quality of the items and if they belong in the factor (Ferrando and Lorenzo-Seva, 2014). Finally, the scale was applied to 1,032 participants, whose responses were subjected to confirmatory factor analysis and other statistical techniques for information processing. In this final application, two tests validated in Peru are incorporated. One, about Loneliness to examine the incremental validity, because it is known that in the face of new measures it is necessary to evaluate its functioning with an available alternative that measures the same or something similar (Hunsley and Meyer, 2003) and a selfesteem scale also validated in Peruvian context to examine the relationship with another variable and provide evidence of the predictive capacity of the BSFL (American Educational Research Association [AERA] et al., 2014).

\section{Analysis of Data}

Statistical analyses were performed with two open access programs: FACTOR version 10.9 for exploratory factor analysis (EFA) and Rstudio version using the 'lavaan' library (Rosseel et al., 2018). In the first stage, a preliminary analysis of the items was carried out considering kurtosis and asymmetry, where values greater than \pm 1.5 would reflect a distortion of normality (Ferrando and Anguiano-Carrasco, 2010).

In the second stage, the dimensionality analysis of the scale was carried out in two modalities: (a) EFA, for which it was necessary to review the sample adequacy measures (KMO and Bartlett's sphericity test). The estimation method was robust unweighted least squares (RULS) with a matrix of polychoric correlations by the ordinality of the data, and for the determination of the number of factors, parallel analysis was used, a simulation technique that compares random values with empirical values (Timmerman and Lorenzo-Seva, 2011); (b) confirmatory factor analysis (CFA) where the following adjustment indices were used ( $\mathrm{Hu}$ and Bentler, 1999): $\chi^{2}$, Root Mean Square Error of Approximation (RMSEA < 0.06), Weighted Root Mean Square Root (WRMR < 1), Comparative Adjustment Index (CFI $>0.95)$ and Tucker-Lewis Index (TLI > 0.95). In addition, the estimator was Weighted Least Square Mean and Variance Adjusted (WLSMV) because it was ordinal data (Brown, 2015). In both types of factor analysis (EFA and CFA), the belonging of an item to a factor was determined by factor loadings greater than or equal to 0.30 (Kline, 2015).

In a third stage, reliability was estimated using the omega coefficient $(\omega)$ that reflects the proportion of common variance shared by the items (Ventura-León and Caycho-Rodríguez, 2017), where values above 0.70 are considered recommendable.

In the fourth stage, factor invariance according to sex was calculated under the recommendations of $\mathrm{Wu}$ and Estabrook (2016), who point out that in the case of ordinal data the invariance cannot be examined only by restricting a set of parameters at a time. In this way, configural invariance (base model), metric invariance (thresholds, loading constrained to be equal across groups), scalar invariance (thresholds, loadings, intercepts) and strict invariance (thresholds, loadings, intercepts, residual) were tested. Theta -parameterization was used which allows the calculation of the residuals (strict invariance). Also, the WLSMV was used as an estimator (Brown, 2015). To observe the suitability of the invariance, minimal differences were established between the two models according to those presented by Finch and French (2018), who point out that an RMSEA $(\triangle \mathrm{RMSEA})<0.01$ is adequate for ordinal variables and what Chen (2007) postulated, where CFI $(\Delta \mathrm{CFI}) \leq 0.01$ is adequate. It is worth mentioning that this continuous cut-off point is 


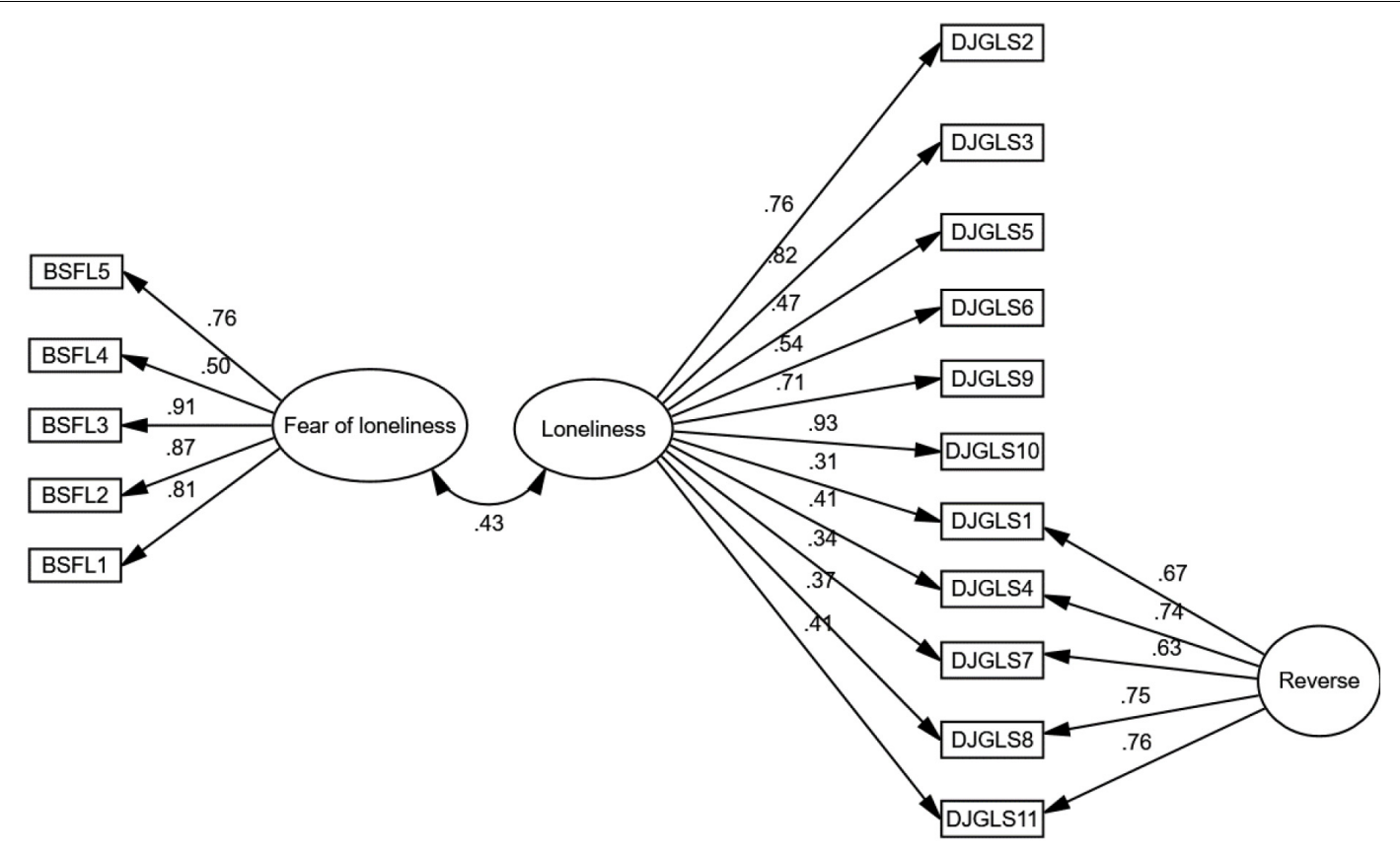

FIGURE 2 | Structural model of the relationship between the BSFL and DJGLS.

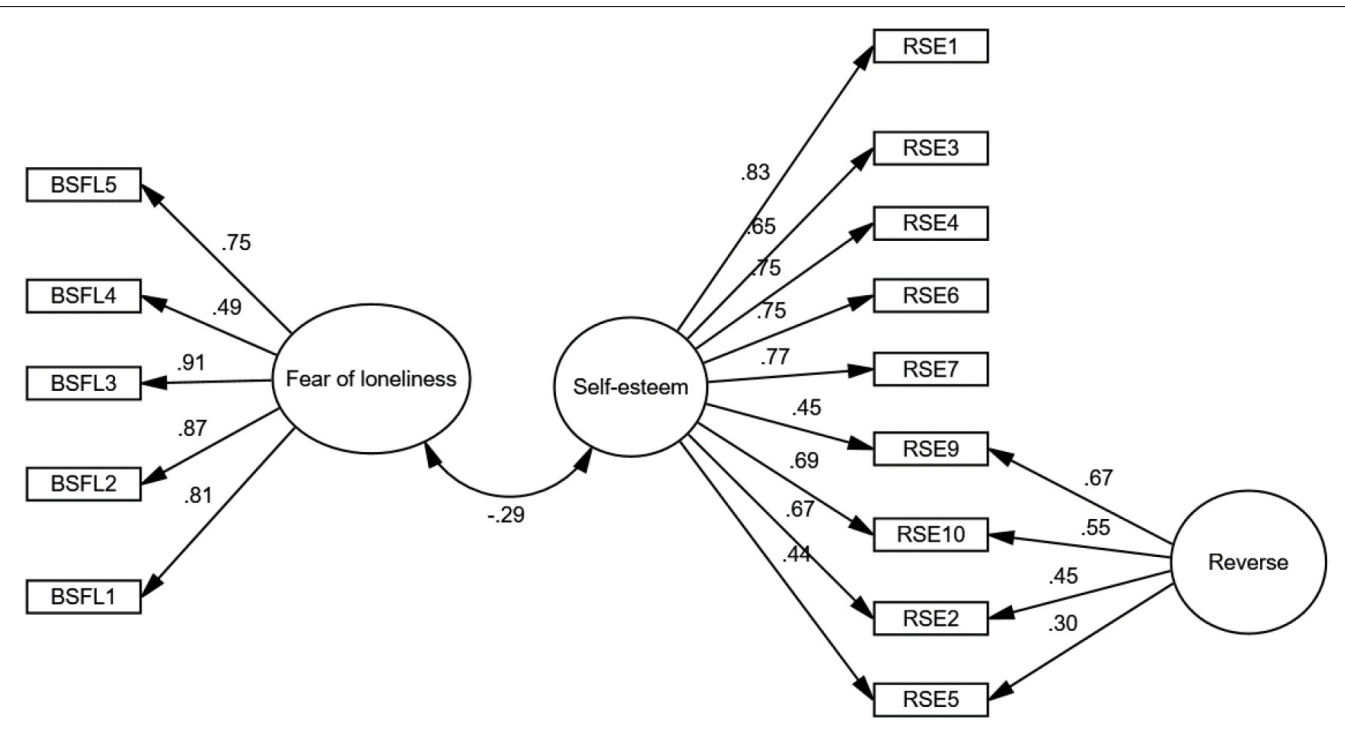

FIGURE 3 | Structural model of the relationship between BSFL and RSE.

TABLE 1 | Descriptive Statistics of the BSFL.

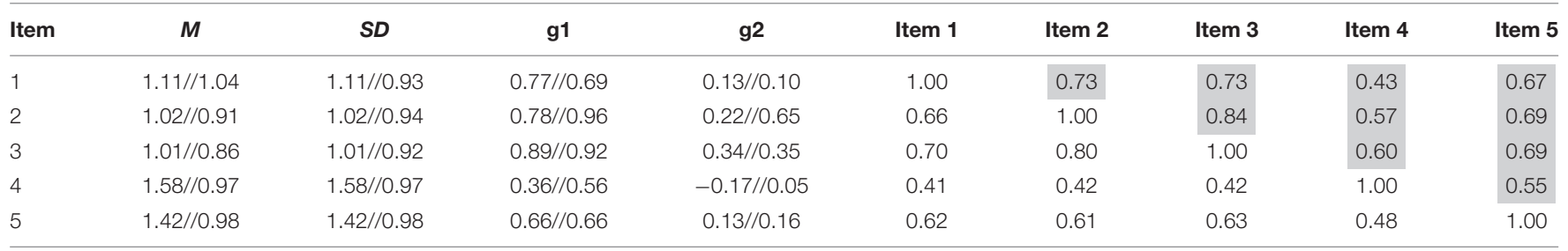

From the//symbol to the left EFA and to the right CFA; From the diagonal down the matrix of the EFA and upward of the CFA. M, mean; SD, standard deviation; g1, asymmetry; g2, kurtosis. 
used because it does not have a categorical version, as there are minimal differences between the models.

The fifth stage consisted of contrasting the evidence in relation to other variables. Therefore, correlations were modeled from SEM with the De Jong Gierveld loneliness scale (VenturaLeón and Caycho, 2017) and Rosenberg's Self-esteem (VenturaLeón et al., 2018), following Cohen's recommendations for the magnitude of the effect (2009) where: $r \geq 0.10$ is small; $r \geq 0.30$ is considered moderate; $r \geq 0.50$ shows a strong effect.

\section{RESULTS}

\section{Evidence Based on Content}

The analysis of the content of the items was carried out by expert judges who rated the scale based on two criteria: (a) Representativeness, indicating the correspondence between the content of the items and the definition of the construct, and (b) Relevance, the importance of including the items on the scale. An Aiken's V of 1.00 is observed for all items in the two criteria, suggesting evidence about the content of the BSFL.

\section{Preliminary Analysis of the Items}

As seen in Table 1, items 4 and 5 have a higher arithmetic mean. All items show kurtosis and asymmetry values below \pm 1.5 (Ferrando and Anguiano-Carrasco, 2010) with positive kurtosis, except for item 4. Additionally, the Mardia coefficient was calculated, which presented a value of 45.98 , which indicates little deviation from multivariate normality.

\section{Evidence Based on Internal Structure}

For the EFA (Table 2), RULS were used, with a polychoric correlation matrix and Parallel Analysis (PA) with optimal implementation (Timmerman and Lorenzo-Seva, 2011). The KMO test (0.83) and Bartlett's sphericity test $\left[\chi^{2}(10)=743.9\right.$, $p<0.001]$ indicated that it is possible to carry out an EFA (Abad et al., 2012).

The PA pointed out the existence of a single underlying factor, which explains $66.68 \%$ of the total variance, with an Eigenvalue of 3.33. Goodness of fit indices were excellent $\left(\chi^{2}=10.70, \mathrm{df}=5\right.$, $p=0.060$; RMSEA $=0.06, \mathrm{CFI}=1.00$. WRMR $=0.05)$. It should be noted that robust Chi square was used with mean and scaled variance (Asparouhov and Muthen, 2010).

The CFA (Figure 1) was carried out with a second group of participants $(N=1032)$ in order to verify what was obtained in the EFA. A single factor structure was modeled that revealed good goodness of fit $\left(\chi^{2}=12.93, \mathrm{df}=5, \chi 2 / \mathrm{df}=2.59, \mathrm{RMSEA}=0.04\right.$, $\mathrm{CFI}=1.00$, TLI $=1.00)$.

\section{Reliability}

Reliability was calculated for each of the moments of the factor analysis. Thus, at the exploratory level the omega coefficient is considered good $(\omega=0.88)$ and at the confirmatory level considered excellent $(\omega=0.91)$. In this way, it can be seen that the factor loads are strong.

\section{Factor Invariance According to Sex}

Table 3 shows the measurement invariance, which was evaluated starting from a base model called configural invariance (M1), metric (M2), scalar (M3), strict (M4), the estimator used WLSMV was robust because it considers ordinal variables (Brown, 2015). In this sense, the base model examined the fit in both groups without restrictions on some of the parameters. Then, the M2 model, which is a model where the loads and thresholds of each item so that they have the same value in men and women. It is seen that the difference between $\mathrm{M} 1$ and M2 are minimal ( $\Delta$ CFI $<0.01$ ), accepting the hypothesis that the thresholds are invariant. Subsequently, invariance in loads, thresholds and intercepts is examined adding restrictions on all items across subgroups (M3). It is observed that the difference between M3 and $\mathrm{M} 1$ is minimal $(\triangle \mathrm{CFI}<0.01)$. Finally, the strict invariance is evaluated where the loads, thresholds, intercepts and residuals are the same in the two groups, examining that the differences are within expectations $(\triangle \mathrm{CFI}<0.01)$.

In view of the fact that factorial invariance was achieved, we proceeded to examine the differences according to sex through the latent means. In relation to the fear of loneliness, it is observed that women $(M=0.85)$ present a slightly higher value than men $(M=0.81)$; although it is not statistically significant and the effect size is trivial $[t(405.89)=0.70$, $p=0.482, d=0.05]$.

TABLE 2 | Standardized factor loadings of the BSFL in the exploratory factor analyses.

\begin{tabular}{|c|c|c|}
\hline Item & $\mathbf{F 1}$ & $h^{2}$ \\
\hline $\begin{array}{l}\text { (1) I fear someone may leave me [Temo que alguien } \\
\text { pueda abandonarme] }\end{array}$ & 0.80 & 0.64 \\
\hline $\begin{array}{l}\text { (2) The idea of being alone worries me [La idea de estar } \\
\text { solo me preocupa] }\end{array}$ & 0.85 & 0.73 \\
\hline (3) I am afraid of being alone [Tengo miedo a estar solo] & 0.88 & 0.77 \\
\hline $\begin{array}{l}\text { (4) When I am alone, I look for someone's company } \\
\text { [Cuando estoy solo, busco la compañía de alguien] }\end{array}$ & 0.52 & 0.27 \\
\hline $\begin{array}{l}\text { (5) I am concerned that someone is leaving my side [Me } \\
\text { preocupa que alguien se aleje de mi lado] }\end{array}$ & 0.76 & 0.57 \\
\hline$\omega$ & 0.88 & \\
\hline $\mathrm{Load} / \mathrm{h}^{2}$ mean & $0.76 / 0.59$ & \\
\hline Eigenvalue & 3.33 & \\
\hline$\%$ of Variance & 66.68 & \\
\hline
\end{tabular}

$h^{2}=$ communality; F1 = Fear of loneliness.

TABLE 3 | Analysis of factor invariance according to the gender of the BSFL.

\begin{tabular}{lcccccr}
\hline Models & $\boldsymbol{\chi}^{\mathbf{2}}(\boldsymbol{d} \boldsymbol{f})$ & $\boldsymbol{\Delta} \boldsymbol{\chi}^{\mathbf{2}}$ & $\boldsymbol{\Delta} \boldsymbol{d f}$ & $\boldsymbol{p}$ & $\mathbf{C F I}$ & $\boldsymbol{\Delta}$ CFI \\
\hline M1 & $31.88(10)$ & - & - & - & - & - \\
M2 & $37.17(20)$ & 7.68 & 10 & 0.011 & 0.99 & 0.001 \\
M3 & $34.58(24)$ & 1.25 & 4 & 0.075 & 0.99 & 0.002 \\
M4 & $41.13(28)$ & 5.88 & 4 & 0.052 & 0.99 & -0.001 \\
M5 & $49.09(33)$ & 6.78 & 5 & 0.035 & 0.99 & -0.001 \\
\hline
\end{tabular}

M1: configural; M2: threshold; M3: metric; M4: scalar; M5: strict. 


\section{Incremental Validity}

The incremental validity of the BSFL was evaluated with a similar test that was validated in the Peruvian context, such as the DJGLS (De Jong-Gierveld and Kamphuls, 1985). In this sense, the results (Figure 2) show a moderate relationship $(r=0.43$, CFI $=0.93$; RMSEA $=0.06$; SRMR $=0.08$ ); which is good, because if the correlation is very high it would imply a conceptual overlap.

\section{Evidence Based on the Relationship With Other Variables}

To evaluate convergence with other tests, a concurrency method was used. In this sense, the scores of the BSFL of the participants were correlated with the RSE (Rosenberg, 1965). The results showed (Figure 3 ) that RSE was negatively correlated with BSFL $(r=-0.29, \mathrm{CFI}=0.94$; RMSEA $=0.07$; SRMR $=0.07)$. In this way, the predictive power of the BSFL is revealed.

\section{DISCUSSION}

Loneliness is a frequent event in youth and adulthood and for many years it has been known that the prevalence reaches 69\% (Parlee, 1979) and that there is a concern about feeling alone in this age group (YOUGOV, 2016). Although there are various instruments that have measured loneliness since the 1970s (Russell et al., 1978, 1980; De Jong-Gierveld and Kamphuls, 1985; Russell, 1996; Cramer and Barry, 1999; Hughes et al., 2004; Maes et al., 2015). There is no instrument that assesses the fear of loneliness. In this sense, the main objective of the present study was to develop and validate a Brief Scale of Fear of Loneliness in Young People and Adults.

Regarding the evidence of validity, the content of the items was reviewed through the judgment of experts who found high representativeness and relevance of the items in the BSFL, which is often a forgotten action, but one that is necessary (International Test Commission [ITC], 2018). This accompanied by the Aiken's V coefficient (Ventura-León, 2019) allowed verifying the quality of the items.

Regarding its internal structure, the BSFL is a one-dimensional measure of fear of loneliness. Thus, the EFA produced with polychoric correlation matrices by the ordinality of the data, revealed that a single factor underlies the five items, which explains $66.68 \%$ of the variance of the construct. Likewise, their factor loads were $>0.30$ (Kline, 2015). These findings were corroborated by the CFA, which showed excellent goodness of fit indices (Hu and Bentler, 1999). Similarly, the assumption of one-dimensionality is consistent with theoretical arguments of previous studies regarding fear of a specific object (Zubeidat et al., 2007; Dongil and Wood, 2009; Ibrahim et al., 2017).

Regarding the reliability of the BSFL, it revealed good values both in its exploratory version $(\omega=0.88)$ and confirmatory $(\omega=0.91)$. These results are consistent with cut-off points established by various authors who suggest that values $>0.70$ are considered acceptable (Ventura-León and Caycho-Rodríguez, 2017).
In relation to incremental validity, a similar test with Peruvian validation was used, as it is a recommendation by Hunsley and Meyer (2003). This in order to observe that if there is a relationship between both tests, that it is not large enough to suppose a conceptual overlap (American Educational Research Association [AERA] et al., 2014). These findings reveal that the BSFL measures something similar to the DJGLS, but not the same; therefore, they are constructs that are associated, but not the same.

To provide evidence based on the relationship with other variables, the convergence of the BSFL was evaluated, which demonstrated its predictability by presenting a moderate correlation ( $r=0.29$;Cohen, 1988) with the loneliness scale adapted to the Peruvian context (Ventura-León and Caycho, 2017) and the self-esteem scale (Ventura-León et al., 2018) showing an expected theoretical direction. Thus, the correlation between loneliness and self-esteem is consistent with previous studies; evidencing that experiencing fear of loneliness is associated in a moderate way with the self-assessment of the self (Brewer and Kerslake, 2015; Błachnio and Przepiorka, 2019; Chiao et al., 2019).

It is important to note that the present study reviewed the gender invariance of the BSFL. The measurement invariances (configurational, thresholds, and factor loads) were stable across the groups. In this sense, the items measure the latent trait in men and women in the same way (Brown, 2015), which is a requirement of the measurement instruments for comparison by groups (Byrne, 2008). Therefore, the one-dimensional structure of the BSFL according to sex, indicates that in the sample of Peruvian youth and adults (men and women) they conceptualize FL in an equivalent way, a situation that suggests that the factor structure is similar in both groups and that the differences between men and women are real and not the product of a measurement bias.

Regarding the theoretical implications, having this scale will allow evaluating theoretical models and seeing the relationship that the fear of loneliness (and not only the feeling of loneliness) has with well-being, the sense of belonging and with the construction of identity of individuals, in a society that becomes more and more individualistic (Santos et al., 2017) and consumer of social networks, which, in some cases, increase people's feelings of loneliness (Song et al., 2014). Regarding the practical implications, the scale developed, due to its reduced number of items, allows a pragmatic and rapid measurement of the fear of loneliness in large populations, which would allow to orient preventive interventions on the psychosocial variables commonly associated with loneliness (drug use, excessive use of the internet, for example).

The study has some limitations. First, more participants are required in the invariance analysis for further studies. Second, it was not feasible to review the temporal stability of the scale; so, a test-retest is recommended in future studies. Third, the participants were people with higher studies, so the scale can only be interpreted for a population with similar characteristics; it is recommended to explore its operation in other populations.

It is concluded that the BSFL is a measure that has evidence of validity, reliability in its scores, being invariant regarding sex and 
predicting other behaviors quite well. Therefore, it is a short selfreported measure, easy and quick to apply, which will be useful in future research studies.

\section{DATA AVAILABILITY STATEMENT}

The raw data supporting the conclusions of this article will be made available by the authors, without undue reservation.

\section{ETHICS STATEMENT}

Ethical review and approval was not required for the study on human participants in accordance with the local legislation and institutional requirements. The patients/participants provided their written informed consent to participate in this study.

\section{REFERENCES}

Abad, F., Olea, J., Ponsoda, V., and García, C. (2012). Medición en Ciencias Sociales $y$ de la Salud. Madrid: Síntesis

Al-Namankany, A., De Souza, M., and Ashley, P. (2012). Evidence-based dentistry: analysis of dental anxiety scales for children. Br. Dent. J. 212, 219-222.

American Educational Research Association [AERA], American Psychological Association [Apa], and National Council on Measurement in Education [Ncme], (2014). Standards for Educational and Psychological Testing. Washington, DC: American Educational Research Association.

Andersson, L. (1993). Loneliness and its relationship with misery. Psychol. Rep. 73, 584-586. doi: 10.2466/pr0.1993.73.2.584

Armfield, J. M. (2010). Development and psychometric evaluation of the Index of Dental Anxiety and Fear (IDAF-4C+). Psychol. Assess. 22, 279-287. doi: $10.1037 / \mathrm{a} 0018678$

Asparouhov, T., and Muthen, B. (2010). Simple Second order Chi-Square Correction. Unpublished manuscript. Available online at: https://www. statmodel.com/download/WLSMV_new_chi21.pdf (accessed March 3, 2020).

Bandura, A. (1977). Self-efficacy: toward a unifying theory of behavioral change. Psychol. Rev. 84, 191-215. doi: 10.1037/0033-295x.84.2.191

Bay, E. J., and Algase, D. L. (1999). Fear and anxiety: a simultaneous concept analysis. Int. J. Nursing Terminol. Class. 10, 103-111. doi: 10.1111/j.1744-618x. 1999.tb00036.x

Bian, M., and Leung, L. (2015). Linking loneliness, shyness, smartphone addiction symptoms, and patterns of smartphone use to social capital. Soc. Sci. Comp. Rev. 33, 61-79. doi: 10.1177/0894439314528779

Błachnio, A., and Przepiorka, A. (2019). Be aware! If you start using Facebook problematically you will feel lonely: phubbing, loneliness, self-esteem, and Facebook intrusion. A cross-sectional study. Soc. Sci. Comp. Rev. 37, 270-278. doi: $10.1177 / 0894439318754490$

Blanchard, R. J., and Blanchard, D. C. (1990a). “Anti-predator defense as models of animal fear and anxiety," in Ettore Majorana International Life Sciences Series, P. F., Brain, S. Parmigiani, R. J., Blanchard, \& D., Mainardi, (Amsterdam: Harwood Academic Publishers). 89-108

Blanchard, R. J., and Blanchard, D. C. (1990b). "An ethnoexperimental analysis of defense, fear, and anxiety"," in Anxiety Otago Conference Series, No. 1, eds N. McNaughton, and G. Andrews, (New Zealand: University of Otago Press), 124-133.

Brewer, G., and Kerslake, J. (2015). Cyberbullying, -esteem, empathy and loneliness. Comp. Hum. Behav. 48, 255-260. doi: 10.1016/j.chb.2015. 01.073

Brown, E. G., Creaven, A. M., and Gallagher, S. (2019). Loneliness and cardiovascular reactivity to acute stress in younger adults. Int. J. Psychophysiol. 135, 121-125. doi: 10.1016/j.ijpsycho.2018.07.471

\section{AUTHOR CONTRIBUTIONS}

JV-L involved in planning and supervised the work, processed data, performed the analysis, drafted the manuscript, and designed the figures. AS-V contributed in preparation of the published work, specifically critical review, commentary. TC-R and MB-P performed the measurements, sample design, aided in interpreting the results, and worked on the manuscript. AR contributed in presentation of the published work, specifically writing the initial draft (including substantive translation). All authors discussed the results and commented on the manuscript.

\section{FUNDING}

This study was financed by CONICYT PIA CIE160009, as well as Universidad Privada del Norte.

Brown, E. G., Gallagher, S., and Creaven, A. M. (2017). Loneliness and acute stress reactivity: a systematic review of psychophysiological studies. Psychophysiology 55:e13031. doi: 10.1111/psyp.13031

Brown, T. A. (2015). Methodology in the Social Sciences. New York, NY: Guilford Press.

Byrne, B. M. (2008). Testing for multigroup equivalence of a measuring instrument: a walk through the process. Psicothema 20, 872-882.

Calati, R., Ferrari, C., Brittner, M., Oasi, O., Olié, E., Carvalho, A. F., et al. (2018). Suicidal thoughts and behaviors and social isolation: a narrative review of the literature. J. Affect. Disord. 245, 653-667. doi: 10.1016/j.jad.2018.11.022

Catherall, D. R. (2003). How fear differs from anxiety. Traumatology 9, 76-92. doi: 10.1528/trau.9.2.76.22259

Chang, E. C., Chang, O. D., Martos, T., Sallay, V., Lee, J., Stam, K. R., et al. (2017). Family support as a moderator of the relationship between loneliness and suicide risk in college students: having a supportive family matters! Family J. 25, 257-263. doi: 10.1177/1066480717711102

Chen, F. F. (2007). Sensitivity of goodness of fit indexes to lack of measurement invariance. Struct. Equat. Model. Multidiscipl. J. 14, 464-504. doi: 10.1080/ 10705510701301834

Chiao, C., Chen, Y. H., and Yi, C. C. (2019). Loneliness in young adulthood: its intersecting forms and its association with psychological well-being and family characteristics in Northern Taiwan. PLoS One 14:e0217777. doi: 10.1371/ journal.pone.0217777

Cohen, J. (1988). Statistical Power Analysis for the Behavioral Sciences (2a ed.). New Jersey, NJ: Erlbaum, doi: 10.4324/9780203771587

Cramer, K. M., and Barry, J. E. (1999). Conceptualizations and measures of loneliness: a comparison of subscales. Personal. Individ. Diff. 27, 491-502. doi: 10.1016/s0191-8869(98)00257-8

Creemers, D. H., Scholte, R. H., Engels, R. C., Prinstein, M. J., and Wiers, R. W. (2012). Implicit and explicit self-esteem as concurrent predictors of suicidal ideation, depressive symptoms, and loneliness. J. Behav. Ther. Exp. Psychiat. 43, 638-646. doi: 10.1016/j.jbtep.2011.09.006

Danneel, S., Bijttebier, P., Bastin, M., Colpin, H., Van den Noortgate, W., Van Leeuwen, K., et al. (2019). Loneliness, social anxiety, and depressive symptoms in adolescence: examining their distinctiveness through factor analysis. J. Child Family Stud. 28, 1-11. doi: 10.1007/s10826-019-01 354-3

De Jong-Gierveld, J., and Kamphuls, F. (1985). The development of a raschtype loneliness scale. Appl. Psychol. Measurem. 9, 289-299. doi: 10.1177/ 014662168500900307

Demirli, A., and Demir, A. (2014). The role of gender, attachment dimensions, and family environment on loneliness among Turkish university students. J. Psychol. Counsellors Schools 24, 62-75. doi: 10.1017/jgc.2013.11

Domagała-Krecioch, A., and Majerek, B. (2013). The Issue of Loneliness in the Period of "Emerging Adulthood", Presented at Eurasian Multidisciplinary Forum, Tibilisi, 2014. Kocani: National and University Library “St. Kliment of Ohrid”. 
Dongil, E., and Wood, C. (2009). El tratamiento de la fobia a volar. Boletín de la SEAS 30, 10-24.

Ferrando, P. J., and Anguiano-Carrasco, C. (2010). El análisis factorial como técnica de investigación en psicología. Papeles del psicólogo 31, $18-33$.

Ferrando, P. J., and Lorenzo-Seva, U. (2014). El análisis factorial exploratorio de los ítems: algunas consideraciones adicionales. Anales de Psicología 30, 1170-1175. doi: 10.6018/analesps.30.3.199991

Finch, W. H., and French, B. F. (2018). A simulation investigation of the performance of invariance assessment using equivalence testing procedures. Struct. Equat. Model. Multidiscipl. J. 25, 673-686. doi: 10.1080/10705511.2018. 1431781

Francis, G. M. (1976). Loneliness: measuring the abstract. Int. J. Nurs. Stud. 13, $153-160$.

Fujimori, A., Hayashi, H., Fujiwara, Y., and Matsusaka, T. (2017). Influences of attachment style, family functions and gender differences on loneliness in japanese university students. Psychology 8:654. doi: 10.4236/psych.2017.84042

Gallego, M. J., Botella, C., Quero, S., Baños, R. M., and García-Palacios, A. (2007). Propiedades psicométricas de la Escala de Miedo a la Evaluación Negativa versión breve (BFNE) en muestra clínica. Rev. de Psicopatol. y Psicol. Clín. 12, 163-176. doi: 10.5944/rppc.vol.12.num.3.2007.4042

Hu, L. T., and Bentler, P. M. (1999). Cutoff criteria for fit indexes in covariance structure analysis: conventional criteria versus new alternatives. Struct. Equat. Model. 6, 1-55. doi: 10.1080/10705519909540118

Hughes, M. E., Waite, L. J., Hawkley, L. C., and Cacioppo, J. T. (2004). A short scale for measuring loneliness in large surveys: results from two population-based studies. Res. Aging 26, 655-672. doi: 10.1177/0164027504268574

Hunsley, J., and Meyer, G. J. (2003). The incremental validity of psychological testing and assessment: conceptual, methodological, and statistical issues. Psychol. Assessment 15, 446-455. doi: 10.1037/1040-3590.15.4.446

Ibrahim, H., Lyons, K. M., Armfield, J. M., and Thomson, W. M. (2017). Performance of the index of dental anxiety and fear in a population-based sample of adults. Aust. Dent. J. 62, 478-484. doi: 10.1111/adj.12541

International Test Commission [ITC], (2018). ITC Guidelines for translating and adapting tests. Int. J. Test. 18, 101-134. doi: 10.1080/15305058.2017.1398166

Kline, P. (2015). A Handbook of Test Construction (psychology revivals): Introduction to Psychometric Design. London: Routledge. doi: 10.4324/ 9781315695990

Kong, F., and You, X. (2013). Loneliness and self-esteem as mediators between social support and life satisfaction in late adolescence. Soc. Indic. Res. 110, 271-279. doi: 10.1007/s11205-011-9930-6

Lasgaard, M., Goossens, L., and Elklit, A. (2011). Loneliness, depressive symptomatology, and suicide ideation in adolescence: cross-sectional and longitudinal analyses. J. Abnorm. Child Psychol. 39, 137-150. doi: 10.1007/ s10802-010-9442-x

López, A., and Calle, I. (2008). Características psicométricas de la Escala de Ansiedad ante la Muerte (DAS) en pacientes de VIH/SIDA. Psicothema 20, 958-963. doi: 10.36576/summa.14329

Maes, M., Klinstra, T., and Van den Neortgate, W. (2015). Factor structure and measurement invariance of a multidimensional loneliness scale: comparisons across gender and age. J. Child Family Stud. 24, 1829-1837. doi: 10.1007/ s10826-014-9986-4

Maes, M., Qualter, P., Vanhalst, J., Van den Noortgate, W., and Goossens, L. (2019). Gender differences in loneliness across the lifespan: a meta-analysis. Eur. J. Personal. 33, 642-654. doi: 10.1002/per.2220

Majorano, M., Brondino, M., Morelli, M., and Maes, M. (2017). Quality of relationship with parents and emotional autonomy as predictors of self-concept and loneliness in adolescents with learning disabilities: the moderating role of the relationship with teachers. J. Child Family Stud. 26, 690-700. doi: 10.1007/ s10826-016-0591-6

Moeller, R. W., and Seehuus, M. (2019). Loneliness as a mediator for college students' social skills and experiences of depression and anxiety. J. Adolesc. 73, 1-13. doi: 10.1016/j.adolescence.2019.03.006

Muyan, M., Ayd $\iota$ n, G. S., and Demir, A. (2018). Predictors of loneliness in turkish university students: shyness and gender. Çukurova Üniversitesi Eð̈itim Fakültesi Dergisi 47, 246-259. doi: 10.14812/cuefd.293221

Ndasauka, Y., Hou, J., Wang, Y., Yang, L., Yang, Z., Ye, Z., et al. (2016). Excessive use of Twitter among college students in the UK: validation of the Microblog
Excessive Use Scale and relationship to social interaction and loneliness. Comp. Hum. Behav. 55, 963-971. doi: 10.1016/j.chb.2015.10.020

Odaci, H., and Kalkan, M. (2010). Problematic internet use, loneliness and dating anxiety among young adult university students. Comp. Educ. 55, 1091-1097. doi: 10.1016/j.compedu.2010.05.006

Parlee, M. B. (1979). The friendship bond. Psychol. Today 13, 43-54.

Perlman, D., and Peplau, L. A. (1981). "Toward a social psychology of loneliness," in Personal Relationships: Vol. 3. Relationships in Disorder, eds R. Gilmour, and S. Duck, (London: Academic Press), 31-56.

Pijpers, J. (2017). Loneliness Among Students in Higher Education: Influencing factors - A Quantitative Cross-sectional Survey research. Universiteit van Amsterdam Student Health Service Research Report. Available online at: https://www.huisartsenamsterdam.nl/wpcontent/uploads/2017/07/Loneliness_Among_Students_in_Higher_Education_ Influencing_Factors.pdf (accessed March 3, 2020).

Real Academia and Española, (2014). Diccionario de la lengua Española, 23 Edn. Available at: http://www.rae.es/rae.html [Accessed June 15, 2020]

Rokach, A. (2000). Loneliness and the life cycle. Psychol. Rep. 86, 629-642. doi: 10.2466/pr0.2000.86.2.629

Rook, K. S. (1984). Promoting social bonding: strategies for helping the lonely and socially isolated. Am. Psychol. 39, 1389-1407. doi: 10.1037/0003-066x.39. 12.1389

Rosenberg, M. (1965). Society and the Adolescent Self-image. Princeton: Princeton University Press, doi: 10.1515/9781400876136

Rosseel, Y., Oberski, D., Byrnes, J., Vanbrabant, L., Savalei, V., Merkle, E., et al. (2018). Package 'lavaan' 0.6-2. Available online at: https://cran.r-project.org/ web/packages/lavaan/lavaan.pdf (accessed March 3, 2020).

Rubin, S. E., Lawlis, G. F., Tasto, D. L., and Namenek, T. (1969). Factor analysis of the 122-item fear survey schedule. Behav. Res. Ther. 7, 381-386. doi: 10.1016/ 0005-7967(69)90068-0

Russell, D. (1996). UCLA Loneliness Scale (Version 3): reliability, validity, and factor structure. J. Pers. Assess. 66, 20-40. doi: 10.1207/s15327752jpa6601_2

Russell, D., Peplau, L. A., and Cutrona, C. E. (1980). The revised UCLA Loneliness Scale: concurrent and discriminant validity evidence. J. Pers. Soc. Psychol. 39, 472-480. doi: 10.1037/0022-3514.39.3.472

Russell, D., Peplau, L. A., and Ferguson, M. L. (1978). Developing a measure of loneliness. J. Pers. Assess. 42, 290-294. doi: 10.1207/s15327752jpa4203_11

Santos, H. C., Varnum, M. E., and Grossmann, I. (2017). Global increases in individualism. Psychol. Sci. 28, 1228-1239. doi: 10.1177/0956797617700622

Simkin, H., and Quintero, S. (2017). Validación de la escala de miedo a la muerte abreviada al contexto argentino. Psocial 3, 53-59. doi: 10.35670/1667-4545.v17. n1.17071

Song, H., Zmyslinski-Seelig, A., Kim, J., Drent, A., Victor, A., Omori, K., and Allen, M. (2014). Does Facebook make you lonely?: a meta analysis. Comp. Hum. Behav. 36, 446-452. doi: 10.1016/j.chb.2014.04.011

Stein, J. Y., and Tuval-Mashiach, R. (2015). The social construction of loneliness: an integrative conceptualization. J. Construct. Psychol. 28, 210-227. doi: 10.1080/ 10720537.2014.911129

Stoliker, B. E., and Lafreniere, K. D. (2015). The influence of perceived stress, loneliness, and learning burnout on university students' educational experience. College Student J. 49, 146-160.

Tian, Q. (2016). Intergeneration social support affects the subjective well-being of the elderly: mediator roles of self-esteem and loneliness. J. Health Psychol. 21, 1137-1144. doi: 10.1177/1359105314547245

Timmerman, M. E., and Lorenzo-Seva, U. (2011). Dimensionality assessment of ordered polytomous items with parallel analysis. Psychol. Methods 16:209-220. doi: $10.1037 / \mathrm{a} 0023353$

Tomás-Sábado, J. (2016). Miedo y Ansiedad ante la Muerte: Aproximación Conceptual, Factores Relacionados e Instrumentos de Evaluación. Barcelona: Editorial Herder.

Tomás-Sábado, J., Limonero, J. T., and Abdel-Khalek, A. M. (2007). Spanish adaptation of the collett-lester fear of death scale. Death Studies 31, 249-260. doi: 10.1080/07481180601152625

Uribe, A., Valderrama, L., and López, S. (2007). Actitud y miedo ante la muerte en adultos mayores. Pensamiento Psicológico 3, 109-120.

Ventura-León, J. L., and Caycho, T. (2017). Validez y fiabilidad de la escala de soledad De Jong Gierveld en jóvenes y adultos peruanos. PSIENCIA. Revista Latinoamericana de Ciencia Psicológica 9:5 
Ventura-León, J. (2019). De regreso a la validez basada en el contenido. Adicciones doi: 10.20882/adicciones.1213 Epub ahead of print.

Ventura-León, J. L., Caycho, T., Barboza-Palomino, M., and Salas, G. (2018). Evidencias psicométricas de la escala de autoestima de Rosenberg en adolescentes limeños. Rev. Int. de Psicol. 52, 44-60. doi: 10.21500/19002386. 3421

Ventura-León, J. L., and Caycho-Rodríguez, T. (2017). El coeficiente Omega: un método alternativo para la estimación de la confiabilidad. Rev. Latinoamericana de Ciencias Soc. Niñez y Juventud 15, 625-627.

Victor, C. R., and Yang, K. (2012). The prevalence of loneliness among adults: a case study of the United Kingdom. J. Psychol. 146, 85-104. doi: 10.1080/00223980. 2011.613875

Whitley, G. G. (1992). Concept analysis of fear. Int. J. Nurs. Terminol. Class. 3, 155-161. doi: 10.1111/j.1744-618x.1992.tb00531.x

Wiseman, H., Guttfreund, D. G., and Lurie, I. (1995). Gender differences in loneliness and depression of university students seeking counselling. Br. J. Guidance Counsell. 23, 231-243. doi: 10.1080/03069889508253008

Wong, P., Reker, G., and Gesser, G. (1997). "Perfil revisado de actitudes hacia la muerte: un instrumento de medida," in Métodos de Evaluación de la Ansiedad ante la Muerte, ed. R. Neimeyer, (Barcelona: Barcelona), $131-156$.
Wu, H., and Estabrook, R. (2016). Identification of confirmatory factor analysis models of different levels of invariance for ordered categorical outcomes. Psychometrika 81, 1014-1045. doi: 10.1007/s11336-0169506-0

YOUGOV, (2016). YouGov Survey Results. London: YouGov.

Zubeidat, I., Salinas, J. M., and Sierra, J. C. (2007). Escala de miedo a la evaluación negativa y escala de evitación y malestar social: fiabilidad y validez en una muestra de adolescentes españoles. Clín. y Salud 18, 57-81. doi: 10.1016/s00257753(02)73419-2

Conflict of Interest: The authors declare that the research was conducted in the absence of any commercial or financial relationships that could be construed as a potential conflict of interest.

Copyright (c) 2020 Ventura-León, Sánchez-Villena, Caycho-Rodríguez, BarbozaPalomino and Rubio. This is an open-access article distributed under the terms of the Creative Commons Attribution License (CC BY). The use, distribution or reproduction in other forums is permitted, provided the original author(s) and the copyright owner(s) are credited and that the original publication in this journal is cited, in accordance with accepted academic practice. No use, distribution or reproduction is permitted which does not comply with these terms. 